\title{
Baseline variability of benthic activity in the Clarion Clipperton Fracture Zone as the basis to assess environmental impacts of deep-sea mining
}

FELIX JANSSEN ${ }^{1}$, ANTJE BOETIUS ${ }^{1}$, MATTHIAS HAECKEL $^{2}$, MASSIMILIANO MOLARI ${ }^{3}$, FRANK WENZHÖFER $^{1}$ AND BATUHAN CAGRI YAPAN ${ }^{3}$

\author{
${ }^{1}$ Alfred Wegener Institute Helmholtz Centre for Polar and \\ Marine Research \\ ${ }^{2}$ GEOMAR Helmholtz Centre for Ocean Research Kiel \\ ${ }^{3}$ Max Planck Institute for Marine Microbiology \\ Presenting Author: felix.janssen@awi.de
}

Sediment community oxygen consumption (SCOC) represents an established bulk measure of benthic activity. It addresses rates of organic matter remineralization as a key function of seafloor ecosystems. SCOC is also explicitly recommended by the International Seabed Authority as a variable for baseline investigations by exploration license holders (document ISBA/25/LTC/6). In preparation for an assessment of environmental impacts associated with the first test of a manganese nodule collector pre-prototype, oxygen flux measurements took place in working areas that were located in the German and Belgian exploration license areas in the Clarion Clipperton Fracture Zone (CCZ) across a spatial scale of approx. $1000 \mathrm{~km}$. The study was carried out in the framework of the European collaborative project MiningImpact under the Joint Programming Initiative Healthy and Productive Seas and Oceans (JPI Oceans). During RV SONNE expedition SO268, rates of total (TOU) and diffusive oxygen uptake (DOU) were quantified in situ with benthic chambers and microprofilers manipulated by remotely operated vehicle (ROV). Within each of the license areas, replicate measurements were obtained at different sites across several kilometers distance. Based on this extensive data set, the presentation aims to assess the requirements (e.g., in terms of replication, relevant spatial scales, methodology) for oxygen uptake observations in the context of environmental baseline studies. Lateral variability in fluxes is addressed as well as differences between total and diffusive fluxes and relations to other biogeochemical data obtained in sediment and pore water samples (e.g., nutrients, organic matter, chloroplastic pigments). Given that a follow-up expedition (,MANGAN 2021') is successfully conducted, first data on immediate effects of mining-related disturbances on benthic oxygen distribution and fluxes will be included in the presentation. 